\title{
EL MOTIVO DE LA PESTE EN CÍANE DE SIRACUSA (1767), DE CÁNDIDO MARÍA TRIGUEROS
}

\author{
Álvaro Ibáñez Chacón \\ Universidad de Málaga \\ alvaroich@yahoo.es
}

\section{RESUMEN}

Cíane de Siracusa es una tragedia neoclásica de Cándido María Trigueros que se encuentra inédita en varios manuscritos. En ella el autor desarrolla el motivo literario de la pestilentiae pictura siguiendo los modelos clásicos (especialmente Sófocles y Séneca) y las tendencias literarias del siglo XVIII.

Palabras Clave: Cíane, Trigueros, tragedia, siglo XVIII

\section{Abstract}

Cíane de Siracusa is a neoclassical tragedy write by Cándido Maria Trigueros and still unknown in several manuscripts. In this work the author develops the literary motif of pestilentiae pictura following classical models (especially Sophocles and Seneca) and the eighteenth-century literary trends.

KEY wORDS: Cyane, Trigueros, Tragedy, Eighteenth Century

Il n'est point de serpent ni de monstre odieux, qui, par l'art imité, ne puisse plaire aux yeux. 
Como la peste, el teatro es el tiempo del mal, el triunfo de las fuerzas oscuras, alimentadas hasta la extinción por una fuerza más profunda aún.

ARTAUD

\section{LA TRAgEdia de Trigueros}

«La personalidad del clérigo dieciochesco don Cándido María Trigueros está integrada en la historia de nuestra cultura con perfiles un poco difusos, en los que se han destacado más bien los trazos negativos. Sin embargo, su portentosa actividad en múltiples frentes intelectuales, su infatigable dedicación al estudio y a la investigación, tanto científica como humanística, su calidad de escritor típicamente neoclásico, le hacen digno de un estudio sereno y libre de prejuicios ${ }^{1} »$.

Así comienza uno de los primeros trabajos que F. Aguilar Piñal dedicó a la figura de Cándido María Trigueros, de quien se ha convertido en el mayor especialista con un elevado de estudios, análisis bibliográficos y edición de obras ${ }^{2}$.

Dejando aparte la típica pasión que nace en el investigador por lo investigado, las constantes reivindicaciones de Aguilar Piñal contra las numerosas críticas recibidas por Trigueros ya desde sus contemporáneos están justificadas si se tiene en cuenta que la mayor parte de la obra de este erudito ilustrado sigue inédita en las bibliotecas españolas y que generalmente Trigueros es conocido como refundidor de obras ajenas y como epigrafista de dudosa fiabilidad ${ }^{3}$.

Según las informaciones de Aguilar Piñal (1987: 178), Cíane es la primera tragedia conservada de Trigueros, pues la carta-prólogo que la encabeza en uno de los mss., dirigida a D. ${ }^{n}$ A. G. de L. ${ }^{4}$, está fechada en Sevilla el 22 de julio de $1767^{5}$. El texto de la tragedia sigue inédito, que sepamos, y precisamente por ello no hay ningún estudio pormenorizado aparte de las breves (y en ocasiones inexactas) anotaciones de Aguilar Piñal (1987: 178-180) y del no exhaustivo análisis de Pabón (1972). Por nuestra parte, hemos tenido en cuenta los tres manuscritos que se conservan en la Biblioteca Nacional de Madrid': ms. 18072, con trece autógrafos de Trigueros (Aguilar Piñal, 1968: 36) y la carta-prólogo ya aludida (hs. 206-214); ms. 16226, sólo con la tragedia de Trigueros, y $m s .17294$, que parece la copia en limpio dispuesta por Trigueros para una posible publicación.

1 Aguilar Piñal, 1968.

2 Su principal trabajo es el estudio bio-bibliográfico Aguilar Piñal, 1987.

3 La refundición teatral fue una tendencia de moda en el siglo XVIII en cierta medida motivada por el interés del público, vid. Andioc, 1975: 402 ss. Además de trabajar sobre comedias de Lope y Calderón, Trigueros continuó la inconclusa novela pastoril La Galatea de Cervantes, vid. Aguilar Piñal, 1987b; de su labor como «fabulador de inscripciones» vid. Gil, 1981: 164-175.

${ }^{4}$ Identificado por Aguilar Pinal (1987: 178) con Antonio González de León, poeta sevillano y hermano del editor de las obras de Trigueros.

5 Cuando Trigueros disfrutaba, pues, del edificante estímulo de la «tertulia del Alcázar» en Sevilla que promovió Olavide; vid. Aguilar Piñal, 1974: 82-85.

6 Aguilar Piñal (1987: 179, n. 104) cita otros dos que aún no hemos podido consultar. 
La tragedia está compuesta de acuerdo con la preceptiva neoclásica ${ }^{7}$, es decir, cimentada sobre las reglas de tres idearios: la Epistula ad Pisones de Horacio, L'Art Poétique de Boileau y la Poética de Luzán, cada uno de ellos origen y punto de partida de una normatividad que, aun remontándose a la Poética aristotélica, no deja de aportar matices con respecto de los precedentes. Pero parece que la personalidad de Trigueros no le permite encasillarse fácilmente; nótese el alegato (claramente prerromántico):

No hablemos de los que sólo son versificadores o de los poetas que solamente tienen ingenio: entre los pocos poetas a quien el cielo concede el sublime don que llamamos genio, cualquiera sabe mejor el arte poética que Aristóteles y todos los demás teoristas; están, digámoslo así, iluminados por su genio. Estudian el arte de los fríos preceptores, toman lecciones de la naturaleza, las toman de sus mejores pintores y el genio escoge entre todo lo que conviene. Las reglas se forman observando lo que hace el genio; el genio no es esclavo de las reglas, lo es solamente de la situación, la razón y la naturaleza. (h. 213r)

No obstante, Trigueros sigue con mayor o menor fidelidad las leyes dramáticas ${ }^{8}$, aunque en la carta-prólogo especifica cuándo se aparta de la preceptiva horaciana ${ }^{9}$ y cuándo de la de Boileau ${ }^{10}$; en cuanto a Luzán, hay un evidente punto de divergencia: a pesar de la gran transcendencia y tradición del teatro mitológico en España ${ }^{11}$, la poética ilustrada desestimó los mitos clásicos por considerarlos inverosímiles y ajenos a la razón ${ }^{12}$, si bien los dramaturgos dieciochescos no se resignaron a eliminar de las tablas otros modelos funcionalmente análogos, de ahí la proliferación de dramas de tema histórico protagonizados por figuras ilustres de la historia de España ${ }^{13}$. Trigueros se desmarca, por tanto, de una norma -más teórica que práctica- ${ }^{14}$ y se decanta por una tragedia mitológica, con el aliciente de tomar la historia de un mito poco conocido y de un compendio poco divulgado ${ }^{15}$.

7 Sobre la tragedia neoclásica véanse las aportaciones de Andioc, 1976: 381-418; Glendinning, 1979: 141167; Palacios Fernández, 1996: 193-200; Cañas Murillo, 2003; Berbel Rodríguez, 2003: 165-222.

${ }^{8}$ En especial la de Luzán (Aguilar Piñal, 1987: 273-278), blasón del antibarroquismo de los «innovadores» de la Academia del Buen Gusto, vid. Sebold, 2008: 70-97; Cañas Murillo, 2003: 1578-1587; Berbel Rodríguez, 2003: 19-96.

${ }^{9}$ Cf. h. 212r: «También habrá alguno que no lleve bien que Cianipo se mate sobre el teatro y que Cíane beba sobre de él veneno. En cuanto a otras tragedias se ha rebatido mucho este asunto y no todos están acordes en que el precepto de Horacio proscriba igualmente todas las muertes sobre el teatro. Mas, sin detenernos en disputas, [...]», a partir de aquí se excusa con la presencia de muertes sobre las tablas en el teatro europeo y con el carácter aleccionador del sacrificio de Cianipo a ojos vista del público.

${ }_{10}$ A Boileau lo cita al hablar de quienes saben de poesía sólo de forma teórica y no han llevado a la práctica sus propios preceptos: «Su espíritu demasiado geométrico y monótono creerá ser un gran defecto lo que parece quebrantar la regla que consagró, digámoslo así, con sus excelentes versos Mr. Boileau, y no creerán lícito apartarse de lo que prescribió el 'Poeta de la Razón', cuando se erigió en 'dictador del Parnaso'. Pero, ¿no quedará alguna apelación al soberano de él? ¿No será lícito solicitar algún privilegio de Apolo? Ello es cierto que Mr. Boileau no escribió tragedias; quizá, si hubiera escrito una Cíane con el plan de éstas, hubiera sido el primero que apelara de su misma ley. Este plan es todo por la razón y la sencillez y, arreglada a él, pide la razón que en aquella escena hablen las personas que hablan» (h. 212v).

11 Vid. Franco Durán, 1998.

12 Cf. Palacios Fernández, 1996: 214-215.

13 Cf. Andioc, 1976: 381 ss.

${ }^{14}$ En efecto, las obras de argumento mitológico también fueron muy abundantes, sobre todo las inspiradas en versiones francesas; el propio Trigueros compuso varias tragedias mitológicas de las que sólo conservamos títulos y referencias vagas, $c f$. Aguilar Piñal, 1987: 180-181.

15 El gusto de Trigueros por las rarezas se puede ejemplificar también con la traducción que realizó de las Narraciones del mitógrafo Conón y que todavía sigue inédita en la Biblioteca Nacional (en el mismo manuscrito que Cíane) y en la Biblioteca de Menéndez Pelayo de Santander. Conón es uno de los mitógrafos 


\section{El ARGUMENTo MitolóGico}

En la carta-prólogo que precede a la tragedia en el ms. 18072, Trigueros incluye una traducción del relato que le ha servido como argumento:

Cianipo de Siracusa había ofrecido sacrificios a todas las deidades menos a Baco, el cual, indignado de esta omisión, le castigó con una embriaguez, mientras la cual violentó a su propia hija Cíane, que encontró en un lugar oscuro. Cíane le quitó del dedo el anillo y le entregó a su aya, para que sirviese de señal, por la cual fuese reconocido su violentador. Sobrevino una peste y, consultado Apolo Pitio, respondió que se sacrificase a los Dioses que ahuyentan los males un hombre que había cometido un incesto. Cíane comprendió el sentido del oráculo, que los demás no percibían, y, arrastrando por lo cabellos a su padre, le quitó la vida y después se dio muerte a sí propia. ${ }^{16}$

Según el propio Trigueros, «Plutarco en el cap. 19 de los Paralelos de Historia trae estas palabras del libro tercero de las Cosas de Sicilia, de Dosíteo» (h. 206r) ${ }^{17}$ y,

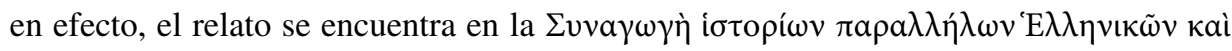

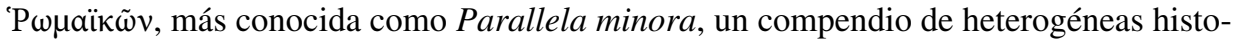
rias falsamente atribuido a Plutarco ${ }^{18}$. Entre otras muchas peculiaridades, el opúsculo se caracteriza por una visión sui generis de la historia antigua, por la invención deliberada de las fuentes y por la presentación de versiones mitográficas aisladas o insólitas ${ }^{19}$; tal es el caso de este mito ${ }^{20}$, cuya versión original, en la edición de De Lazzer (2000: 246), es como sigue:

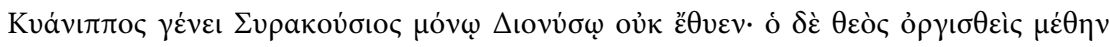

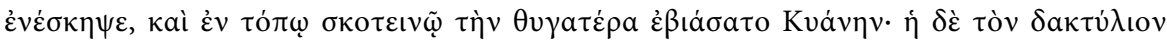

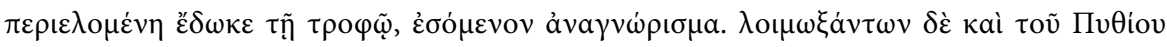

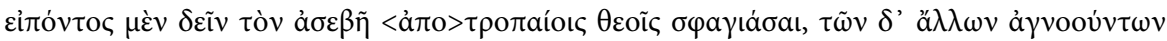

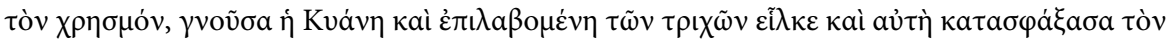

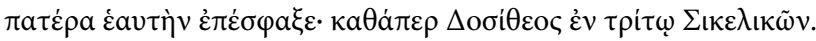

más enigmáticos de la Antigüedad y su obra se conserva sólo a partir del resumen del Patriarca Focio de Constantinopla ( $c f$. Ibáñez Chacón, 2007), pero fue recopilada en varias ediciones antológicas y de ellas pudo Trigueros conseguir el texto; el único estudio dedicado a esta traducción es el de Aguilar Piñal, 1987c, de quien disentimos en algunos aspectos.

16 Aquí, como en el resto de citas extraídas de la obra manuscrita de Trigueros, normalizamos la ortografía según las reglas actuales; la escritura de Trigueros se caracteriza por el abuso de abreviaturas y la vacilación ortográfica de b/v, m/n, g/j, i/y, x/j, qu/c, x/s, etc.

17 Erróneamente, Aguilar Piñal (1987: 179) identifica esta obra con las Vidas Paralelas de Plutarco, pues los Parallela minora se insertan en el heterogéneo corpus de los Moralia.

18 Vid. Jacoby 1940; Ziegler 1965, pp. 274-277; De Lazzer 2000; Ibáñez Chacón 2012.

19 Cf. Ibáñez Chacón, 2010, con bibliografía.

${ }^{20}$ La ninfa Cíane está asociada a Siracusa en las fuentes griegas ( $c f$. D. S. IV 23.4-5; Ael. VH 2.33), pero es Ovidio quien le dotó de personalidad en su dos versiones del rapto de Perséfone, vid. Ou. Met. 5.409-436 y Fast. 4.417-620. Además, queda abierto un capítulo interesante de investigación a partir del P. Berol.inv. 11 056, que parece contener un pequeño fragmento de una novela con Cíane como protagonista (vid. Müller, 1981; Luppe, 2001); agradecemos a la Prof. M. ${ }^{\text {a }}$ Paz López Martínez (Universidad de Alicante) el habernos puesto sobre la pista de este fragmento. 
Además de las amplificationes de Trigueros para hacer más comprensible el texto griego $^{21}$, nótese que el relato contiene elementos típicos de la tragedia griega y de relatos

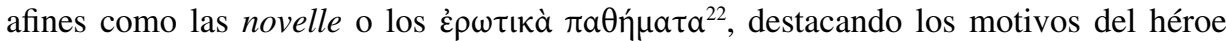
teómaco, la violación de la doncella, la colaboración de la nodriza, la consulta oracular y el suicidio ${ }^{23}$.

La idoneidad de la historia para montar una tragedia es evidente ${ }^{24}$, pues contiene, además, dos temas recurrentes del llamado pre-Romanticismo: el incesto y el suicidio ${ }^{25}$, de manera que Trigueros compone su tragedia partiendo de este argumento mitológico, pero conformando la trama según unos modelos clásicos: principalmente el Edipo rey de Sófocles ${ }^{26}$ y, como se verá en las anotaciones siguientes, también hay mucho del Edipo de Séneca, aunque no ha sido señalado hasta ahora ${ }^{27}$.

\section{Pestilentiae PICTYRA}

La descripción de la epidemia en la tragedia de Trigueros es una amplificatio de la breve alusión que se hace en el argumento pseudoplutarqueo a la peste que asola Siracu$\mathrm{sa}^{28}$, por lo que el erudito ilustrado recurre para su elaboración poética a toda la tradición literaria clásica, siempre con Sófocles y Séneca como pilares de la composición. Aunque se tiene conocimiento de la peste desde el final de la escena $1 .^{\mathrm{a}}$ del acto $3 .^{\circ}$ no es hasta la escena $1 .^{\mathrm{a}}$ del acto $2 .^{\circ}$ cuando Trigueros desarrolla su personal visión de la peste literaria, una descripción que debió sufrir varias críticas y de las que el autor se defiende en el punto $11 .^{\circ}$ de la carta-prólogo (h. 214r):

11. La pintura de la peste ha sufrido tres reprehensiones: $1 .^{\circ}$ no está, dicen, en su lugar, pues no está en el $4 .^{\circ}$ acto; $2 .^{\circ}$ está en la boca de un actor subalterno, que no siendo de habilidad, es de sospechar canse con ellas; $3^{\circ}$ y esto es tanto más de temer cuanto la pintura o descripción es muy larga. Pero si la descripción de la peste no se hace cuando es forzoso decir a Pergandro que la hay y cuáles son sus efectos y disculpar con ellos el frío acogimiento de que se queja, no sé yo cuál otro tiempo será a propósito y, aunque las descripciones se suelen

${ }^{21}$ Si no es que, como sospechamos, Trigueros está traduciendo a partir de una de las muchas versiones latinas de los Moralia y, de hecho, conservaba una edición de la traducción latina de Xylander en su cuarto, cf. Aguilar Piñal, 1999: 113.

${ }_{22}$ Vid. el análisis de textos similares que ofrece Pellizer, 1991: 59-75.

${ }^{23}$ Todos estos motivos son recurrentes en los 41 pares de narraciones que conforman el compendio, especialmente la violación ( $c f$. Ibáñez Chacón, 2008/2009) y la consulta oracular ( $c f$. Fernández Delgado, 1996).

${ }^{24}$ Como un interesante juego intertextual cabría tener en cuenta que en Italia desde el siglo XVI se conocen varias obras dramáticas con este mito como argumento: Cianippo (1596) de A. Michele, Ciane e Cianippo, overo, Gli Oraculi (1785) de G. Del Mare, Cianippo (1806) de G. Pindemonte, todos ellos someramente analizados por Ventricelli, 2004.

${ }^{25}$ Vid. Sebold, 1973, que desarrolla su estudio a partir, precisamente, de una «comedia lacrimosa» de Trigueros, El precipitado, sobre la cual $c f$. García Garrosa 1992.

${ }^{26}$ Así lo señala el propio Trigueros en la carta-prólogo: «la acción es una, grande, digna y completa, y substancialmente tiene las mismas circunstancias que el Edipo de Sófocles» (h. 207r).

${ }_{27}$ Pabón (1972) ve, además de reminiscencias de otros dramas clásicos, cierta influencia calderoniana.

${ }^{28}$ Efectivamente, el padecimiento de la peste aparece indicado en el texto pseudoplutarqueo sólo con el

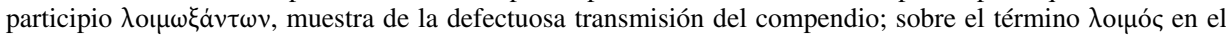
corpus Plutarcheum vid. Pino Campos, 2007, así como el análisis semántico y lexicográfico de las diferencias

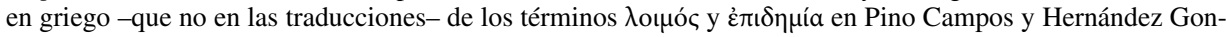
zález, 2008. 
colocar al fin de la pieza, ni es esta regla indispensable, ni son de la clase y con el objeto de la nuestra las que allí se ponen. En cuanto a lo segundo, no podrá oponer este reparo quien sepa y reflexione que la Corifea -o primera actriz del Coro- es personaje tan principal en la representación del drama como Pergandro y Ifianasa, siendo, por otra parte seguro, que uno de los motivos de poner pocas personas en las tragedias es porque ningún actor sea endeble. En fin, si se cree larga esta descripción, su autor no se negará a quitar lo que se pruebe estar de más en ella; mas, a su parecer, aún no tiene toda la extensión que debiera.

Trigueros tiene in mente, sin duda, toda la «literatura loimológica» que desde las Sagradas Escrituras o la Ilíada ha ido configurando una serie de tópicos recurrentes en un heterogéneo corpus $^{29}$, destacando, por la influencia ejercida en determinados contextos, Tucídides ${ }^{30}$, Lucrecio $^{31}$, Virgilio ${ }^{32}$, Ovidio ${ }^{33}$ y Boccaccio $^{34}$. No obstante, hay cierta originalidad en la versión de Trigueros, pues, por un lado, obvia elementos típicos de las descripciones loímico-literarias, mientras que, por otro, amplifica el modelo sofocleo incorporando elementos procedentes de su vasta erudición. La influencia de estos y otros autores en la configuración del motivo literario se aprecia claramente en sus principales elementos constituyentes.

\section{III.1 Origen}

El origen de la peste en la tragedia de Trigueros es de tipo religioso, un castigo de los dioses a raíz del ultraje cometido por Cianipo, de modo que se aparta de las versiones racionalistas que describen la etiología de la epidemia como una conjunción de factores atmosféricos, especialmente de humedad y calor $^{35}$, y se alinea en la tradición mitopoética de las epidemias, remontable en la literatura occidental a la peste enviada por Apolo al campamento aqueo como castigo por las penalidades causadas a su sacerdote Crises $^{36}$.

29 Vid. Büchner, 1957: 67-79; Grimm, 1965; Steel, 1981; Ramírez de Verger, 1985.

30 Th. II 48-54, de quien se dice que dependía de la teoría y terminología científica del Corpus Hippocraticum, aunque, como señaló Alsina (1987), no cabe duda del valor «literario» (= poético) del texto tucidideo y de su relación con el dramatismo de Sófocles. Por otra parte, la identificación exacta de la enfermedad que asoló Atenas ha sido objeto de una prolífica bibliografía recopilada y comentada por Torres Esbarranch, 1989.

${ }^{31}$ Lucr. VI 1093-1286, que sigue a Tucídides y es el punto de partida para la descripción epidémica en latín; léase con el minucioso comentario de Bailey, 1986: 1717-1744.

32 Verg. G. 3.474-566, creación poética condicionada por el modelo de Lucrecio, vid. West, 1979; Harrison, 1979.

${ }^{33}$ Ou. Met. 7.523-613, que fusiona la tradición loímica precedente ( $c f$. Anderson, 1972: 299-308) como pretexto narrativo para la presentación de la correspondiente metamorfosis: Egina ha quedado despoblada y Júpiter crea la raza de los Mirmídones a partir de hormigas, $c f$. Pomelli, 2010

${ }^{34}$ Bocc. Dec. 1.2-48; parece que, como soporte a su experiencia ante la peste de 1348, Boccaccio se sustentó en recreaciones literarias como la de Paul. Diac. Hist. Lang. 2.4 de la epidemia de época justinianea, cf. Branca, 1975: 39.

35 Así a partir sobre todo de Lucr. VI 1090-1137, que acentúa lo adverso de la climatología para el contagio; la idea se repite, por ejemplo, en Verg. G. 3.478-481 o Amm. Marc. XIX 4.1-2 (vid. Ruiz Castellanos, 2012). Sin embargo, para Ou. Met. 7.528-535; Liu. III 6.2-3; V 13.4-7; XXV 26.7; Sen. Oed. $37-52$ o Sil. Ital. XIV 584-594 la pestilencia ambiental es efecto, no causa de la epidemia. Tucídides (II 48.3), por su parte,

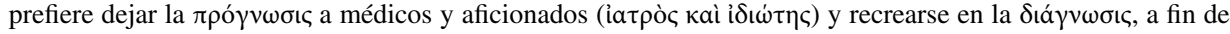
ofrecer un cuadro sintomatológico lo suficientemente detallado como para poder reconocer la enfermedad en caso de un rebrote (como ciertamente ocurrió en el 427 a. C.).

${ }^{36}$ Hom. Il. 1.9-54. 
El origen divino es, por tanto, el tópico recurrente en la mayoría de las descripciones con pretensión poética, dándose numerosas variantes: Ovidio especifica que la causa de la peste en Egina está en la ira Iunonis, siempre vengativa con las amantes de Júpiter ${ }^{37}$; Livio, por su parte, recoge el maestum responsum de la deum ira como causa de la peste del 463 a. C. durante la guerra con los ecuos ${ }^{38}$ o en la epidemia acaecida el 399 a. C. en plena guerra con los veyos ${ }^{39}$, mientras que, para la peste surgida en el 384 a. C., el historiador añade el motivo por el que los dioses están airados: la pena capital ejecutada a $\mathrm{T}$. Manlio Capitolino, precipitado desde la roca Tarpeya por haber promovido una revuelta de plebeyos ${ }^{40}$; para Silio Itálico, en cambio, no hay ira propiamente dicha, sino pura inuidia $^{41}$, otro tópico bien atestiguado el de la «envidia de los dioses» ( $\varphi \theta$ óvoc $\theta \varepsilon \tilde{\omega} v$ ) ante la prosperidad y la felicidad de los demás ${ }^{42}$, como ya se lo recriminaba Calipso a

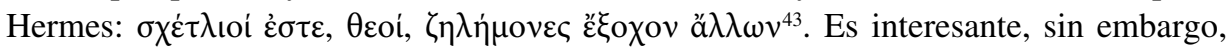
que en Edipo rey, aunque se sabe claramente que la causa última de la pestilencia es la muerte no ajusticiada aún de Layo, en realidad no se especifica el agente pestífero, como tampoco hay una entidad divina concreta en el Edipo de Séneca, sino que la peste se achaca al Fatum, al destino ineludible que maquina males contra el todavía ignorante héroe $^{44}$. No obstante, a pesar de estos visos de racionalización del embiste divino, la mano ejecutora de los dioses se ha afincado tras las epidemias y así figura, como no podía ser de otra manera, en la tradición cristiana ${ }^{45}$ :

[...] llegó la mortífera peste; que o por obra de los astros celestes o por nuestras iniquidades, enviada por justa ira de Dios sobre los mortales para nuestra enmienda, tras comenzar unos años antes en los países orientales, y tras privarles de una innumerable cantidad de vidas, propagándose sin cesar de un lugar a otro, se había extendido miserablemente. ${ }^{46}$

En este sentido, la peste ha pasado a formar parte del terror colectivo desde la Edad Media, debido a la enorme mortandad que las desastrosas epidemias produjeron en la Europa medieval, dando origen a un sinfín de simbolismos, expresiones artísticas y manifestaciones religiosas fruto de las impactantes vivencias de los supervivientes de tan mortíferas catástrofes ${ }^{47}$.

${ }^{37}$ Ou. Met. 7.523; la región de Egina recibió el nombre de una náyade homónima raptada por Zeus y de ahí la cólera de Hera, un leitmotiv de la mitología en general y de las Metamorfosis en particular, cf. Segal, 2005: LXX.

${ }^{38}$ Liu. III 6.5.

${ }^{39}$ Liu. V 14.4.

${ }^{40}$ Liu. VI 20.

41 Sil. Ital. XIV 583.

${ }^{42}$ Cf. Arist. Rh. 1387b 22.

${ }^{43}$ Hom. Od. 5.119.

${ }^{44}$ Sen. Oed. 28; también atribuye el mal al fatum Lucan. VI 98; Manil. I 880-895 extiende ese poder fatídico a los astros en general; Coripp. Ioh. 3.337 combina la envidia y los hados: inuidia sunt misero fatorum stamina mundo.

45 Ya en el Apocalipsis (6.5-8) el cuarto jinete tiene la potestad de desatar la peste sobre la tierra; Isidoro de Sevilla (Etym. 4.6.17), aun admitiendo el origen natural de la peste, apostilla: tamen sine arbitrio omnipotentis Dei omnino non fit.

46 Bocc. Dec. I 8, trad. de Hernández Esteban, 2011.

47 Una magnífica exposición de todos los aspectos destacados de la peste en el pensamiento colectivo europeo en Delumeau, 2012: 129-182 y más sintético Mitre Fernández 2004: 111-134. 
En Cíane el origen de la peste es también divino y punitivo, pero como el asunto de la tragedia es totalmente pagano, no hay ningún tipo de referencia cristiana. Resulta interesante que, a pesar de la omnipresente religión católica y de la temible censura inquisitorial, no haya en toda la tragedia ningún tipo de fusión, interpretación alegórica o evemerista del paganismo; una muestra, quizá, de la superación, al menos por parte de Trigueros, de determinados clichés exegéticos empleados desde la Antigüedad tardía para conciliar ambas culturas y que en épocas precedentes alcanzaron una sistematización considerable ${ }^{48}$, aunque también podríamos apelar al concepto de «connaturalización», término acuñado por Tomás de Iriarte para el acto de traducción y que consiste en la plena adaptación del texto de partida al contexto del receptor, a fin de que el producto final alcance originalidad y autonomía independientemente del modelo ${ }^{49}$. En este sentido, la tragedia de Trigueros está perfectamente «connaturalizada» con la cultura pagana y el agente sancionador son los dioses y la divinidad mediadora Apolo en su sede délfica:

\section{ARQuitas}

Señor, llegué en tu nombre religioso y colgué vuestras dádivas del templo; hiciéronse devotos sacrificios, en que fueron siniestros los agüeros; después de reiteradas peticiones, al fin bajó del cielo el santo fuego y, agitando su voz y su semblante, nos respondió la Pitia en estos versos: «la peste es un castigo de los dioses por un crimen sacrílego y horrendo; cesará su furor y sus desdichas si con la muerte lo pagare el reo».

La escena está inspirada en Sófocles, pero por la disposición exacta previa a la intervención del Coro, Trigueros sigue aquí a Séneca ${ }^{50}$ y tampoco revela el agente pestífero todavía $^{51}$, sino que hay que esperar bastante en el desarrollo de la trama para que señale claramente que la deidad castigadora es Baco. Ahora bien, el carácter «epidémico» de Dioniso/Baco tiende hacia otros ámbitos en el complejo entramado ritual dionisíaco ${ }^{52}$ y en absoluto se manifiesta como una divinidad pestífera en Roma, donde su culto, vulgari-

48 Véase, de forma general, Seznec, 1983.

49 Sobre lo cual vid. Sebold, 2001: 101-119.

50 Cf. Sen. Oed. 205-290.

${ }^{51}$ No obstante, la propia Cíane vislumbra las conexiones entre acción (violación) / reacción (cólera divina) / repercusión (epidemia):

CíAne

¡Cómo parece que los dioses toman en Siracusa la venganza de mi dolor! Desde la misma noche de mi afrenta empezó la peste avara a esparcir el dolor y la tristeza.

52 Vid., entre otros, Jeanmaire, 1970² Detienne, 1986. 
zado en los Bacchanalia, asumió unas expresiones particulares ${ }^{53}$; no obstante, Trigueros conoce bien el desarrollo tradicional de la condenada festividad báquica, tal y como queda reflejado en los siguientes versos:

\section{CÍANe}

[...]

Ya tú sabes que en este santo tiempo

al dios que en él veneran entregadas

las gentes todas, reina la licencia,

reina el desorden, reina la algarada.

En medio del motín que llaman santo,

vagando por el bosque ebrias, turbadas,

con furores y grita abominable,

celebran este día o lo profanan.

Los efectos de Baco los conoces.

¡De qué negros delitos fue la causa!

¡De cuántas muertes, cuántas tiranías!

¡De cuántas violencias y desgracias! ${ }^{54}$

La acusación directa de la venganza de Dioniso/Baco se encuentra en la escena $5 .^{\mathrm{a}}$ del acto $1 .^{\circ}$ en una intervención coral escrita por Trigueros, a la manera de los clásicos ${ }^{55}$, con un lenguaje enigmático y luctuoso:

CORO

¿Para qué nos traéis, dioses sagrados,

a ser testigos de desolamientos?

Baco, el grande, Dioniso, a quien servimos,

nos manda que vengamos a ese puerto

para ver el horror de sus venganzas,

que han de causar horror al universo.

[390]

Por tener ofendido el rey a Baco,

probó en justo castigo de su exceso

sus cálidos efectos poderosos

y un crimen cometió que no sabemos.

A saberlo y hacer que se descubra

53 Vid. Pailler, 1995.

${ }^{54}$ Semejante descripción de las bacanales está en consonancia con lo narrado por Liv. XXXIX 8-19; acerca de las implicaciones sociales, políticas y religiosas de la prohibición de los Bacchanalia en el año 186 a. C. vid. Pailler, 1988.

${ }^{55} C f$. h. 213v: «El coro sirve para prevenir, acompañar y apresurar el desen[lace]; contribuye a dar, sin afectación, un no sé qué de maravilloso. [Es] también oficio suyo dar algún descanso a los actores, hacer [vi] sibles los cinco actos y que, no obstante esto, se haga por [él] palpable que jamás se desampara la escena y que la unidad de tiempo y lugar sobrevivían con el más escrupuloso rigor. Sirve para ministrar en el sacrificio, para acompañar las ceremonias, para adorno en toda la pieza». Además, los intermedios corales son cantados, de manera que también en ello se aparta Trigueros de la tendencia neoclásica de relegar el canto y la música de la tragedia, $c f$. Berbel Rodríguez 2003: 205-206. 
nos manda venir Baco. ¡Oh dios tremendo!

¿Para qué, repetimos, nos envías

a ser testigos de desolamientos?

En este sentido, Trigueros realiza un interesante juego malabar de referencias intertextuales: por un lado, está la narratio pseudoplutarquea, que le ha servido de argumento y donde lo dionisíaco tiene un claro papel vengativo y sancionador por el descuido ritual de Cianipo ${ }^{56}$, y, por otra parte, influyen los modelos genéricos a partir de los cuales Trigueros ha compuesto la trama, pues tanto en Sófocles como en Séneca se redunda en el contexto dionisíaco que favorece la localización espacial del drama en la ciudad de Tebas, tradicionalmente asociada a Dioniso, nieto de Cadmo, mítico fundador de la ciudad; de aquí, por ejemplo, la alusión senecana a la historia mítica de Baco como excursus previo a la descripción de la peste tebana:

\section{CORO}

Te estás muriendo, noble raza de Cadmo, con toda la ciudad; vacías de colonos ves tus tierras, lamentable Tebas.

La muerte, Baco, devora a esos soldados tuyos que te acompañaron hasta los lejanos indos y osaron cabalgar por las regiones de Oriente y clavar tus enseñas en donde amanece el mundo: ellos vieron a los árabes ricos en bosques de canela, y las flechas que lanzan hacia atrás los jinetes, las temibles espaldas del engañoso Parto; ellos penetraron en las costas del mar Rojo, de donde Febo hace surgir el día y despliega su luz y con sus llamas más cercanas oscurece a los desnudos Indos. ${ }^{57}$

El amplio conocimiento de la tradición clásica de Trigueros nos permite aventurar incluso influencias menos evidentes, pero que no dejan de ser significativas: la descripción que Silio Itálico hace de la peste se sitúa precisamente en Sicilia, sufrida por los cartagineses en los últimos momentos de la Segunda Guerra Púnica, y así es introducida por el poeta:

\footnotetext{
El Titán portador de rayos plagó los aires con ardientes calores y con el hedor estigio del Cocito a la anchurosa Cíane, encharcada, rebosante por las cenagosas aguas. ${ }^{58}$
}

56 Tópico de la mitografía clásica en tanto que germen de un castigo divino que en la mayoría de los casos deviene en una catástrofe pandémica, ya sea una auténtica peste, ya la devastación por terremotos, inundaciones, plagas, etc., vid. Parker, 1983: 235-256.

57 Sen. Oed. 110-123, traducción de Pérez Gómez, 2012. Séneca desarrolla el mito de la expedición oriental de Dioniso en la reafirmación de su identidad como hijo de Zeus, un tema que tuvo gran trascendencia a partir de Las bacantes de Eurípides (vv. 1-63) y de la tradición historiográfica helenística, que lo empleó para dignificar los alardes divinizadores de los monarcas a partir de Alejandro Magno, vid. Lens Tuero, 2003.

58 Sil. Ital. XIV 585-587, traducimos según la edición de Martin y Devallet, 1992. En el cuarto de Trigueros se encontraron dos ejemplares de los Punica: la edición latina de 1578 y una traducción francesa de 1781; cf. Aguilar Piñal, 1999: 120. 
Así pues, todo el motivo literario se encuentra perfectamente justificado desde el punto de vista argumental (pseudo-Plutarco) y modélico (Sófocles, Séneca) y también confirmado por numerosas referencias avaladas por la erudición de Trigueros: la descripción de la peste realizada por el Académico no es otra cosa que un mero recurso literario, un tópos vacío de la espontánea autopsia de Tucídides o incluso de Boccaccio ${ }^{59}$ y, por lo tanto, se muestra como un simple artificio poético basado en una sólida tradición precedente.

\section{III.2 Los animales}

La ausencia más significativa del relato de Trigueros es el efecto de la peste en los animales, un tópico recurrente desde Homero incluso en las descripciones epidémicas reales que acentúan su carácter epizoótico ${ }^{60}$. En este punto, la versión más detallada es la de Virgilio, seguido en muchos puntos por Ovidio o Séneca ${ }^{61}$; pero a Trigueros no le interesan los efectos de la peste en los animales, como tampoco pretende exponer una sintomatología detallada de los estragos de la enfermedad en la salud humana, sino que su modelo directo es Sófocles, quien presenta un relato científicamente menos descriptivo y con mayor interés en los efectos cívicos de la epidemia $^{62}$.

\section{III.3 La noche}

Aunque hay constantes referencias mitopoéticas a la noche, Trigueros ha aprovechado la nocturnidad tópica del argumento báquico, fusionándola con el modelo trágico de Séneca, que precisamente comienza:

EDIPO
Expulsada ya la noche, vuelve indeciso Titán
y de una nube tenebrosa surge su siniestra claridad, y cuando con su luctuosa llama esparza una triste luz contemplará las casas asoladas por la peste insaciable y el día mostrará los estragos que la noche ha causado. ${ }^{63}$

\subsection{El mal cívico}

Trigueros redunda en el efecto de la enfermedad sobre la comunidad en general, un aspecto que ya aparece en Homero y que Tucídides, a pesar de centrarse en los estragos

\footnotetext{
59 Cf. Branca, 1975: 39.

${ }^{60}$ Hom. Il. 1.50-53; Th. II 50.1-2; Lucr. VI 1215-1224; Paul. Diac. Hist. Lang. 2.4; Bocc. Dec. 1.17-18.

${ }^{61}$ Verg. G. 3.474-566; Ou. Met. 7.536-550; Sen. Oed. 131-153.

${ }^{62}$ S. OT 169-189; para Pl. Leg. 906c la peste es a la naturaleza lo que la injusticia a la pólis.

63 Sen. Oed. 1-5, trad. Pérez Gómez, 2012.
} 
corporales del individuo, plasma en la idea de la aglomeración pestilente en la ciudad ${ }^{64}$ (cf. infra); sin embargo, en la versión setecentista se aprecia un acento patriótico más en consonancia con los modelos trágicos, quienes presentan a un Edipo gobernante preocupado por su pueblo y dispuesto a todo por su salvación, aunque, paradójicamente, ésta pase por su propia perdición ${ }^{65}$.

\section{III.5 La afección individual}

De la comunidad se pasa Trigueros a describir la tragedia humana individual de la peste, amplificando los modelos clásicos; éstos se centraban en los devastadores efectos de la enfermedad, sobre todo, en las mujeres, cuya esterilidad y luto son el resultado de la respiración prolongada de los aires pestíferos, como si de una moderna contaminación nuclear se tratase ${ }^{66}$. Trigueros va enlazando una serie de relaciones personales truncadas por la peste (vv. 440 ss.), hasta llegar a la «viuda madre congojada y triste» que ve morir en sus brazos al hijo todavía lactante (vv. 450-459), todo ello inspirado en la descripción que hace el propio Edipo senecano:
Ninguna parte queda inmune, libre de destrucción,
mas todas las edades y los sexos perecen por igual
y la funesta peste une a jóvenes y ancianos,
a los padres con los hijos. Una sola antorcha hace arder a los esposos
$y$ a los funerales les faltan sus amargos llantos y lamentos.
Más aún, la misma obstinada ruina de esta desgracia tan grande
ha secado los ojos y, como sucede en los casos extremos,
se han agotado las lágrimas. A uno lo lleva su padre enfermo
hasta la última hoguera, a otro lo conduce la madre enloquecida
que se apresura a traer otro hijo a la misma pira.
Más aún, en un mismo duelo surge un nuevo duelo
y los que acompañaban al cadáver caen alrededor de él. ${ }^{67}$

\section{III.6 Omnia mors aequat}

En este parlamento de Séneca se encuentra otro tópico común a la mayoría de las recreaciones literarias de la peste: omnia mors aequat ${ }^{68}$, y semejante universalidad de la contagiosa muerte la expresa Trigueros, siguiendo a sus fuentes ${ }^{69}$, a lo largo de su descripción con la redundancia de términos que refieren la totalidad y equidad de los efectos

${ }^{64}$ Th. II 52.1.

${ }^{65}$ Una síntesis de las diferencias entre Sófocles y Séneca en su presentación de Edipo en Pérez Gómez, 2012: 667-675; el personaje de Éaco en las Metamorfosis también contiene elementos del buen gobernante y a sus ruegos Júpiter le concede una nueva población: los Mirmídones u «hombres-hormiga».

${ }_{66}$ Cf. S. OT 171-188; sobre el efecto dramático de la pena maternal vid. Loraux, 2004.

67 Sen. Oed. 52-63, trad. Pérez Gómez, 2012.

${ }^{68}$ Expresión de Claud. Rapt. Pros. 2.302, pero de factura horaciana: Od. 1.4.131-134, convertida en un tópico literario de gran trascendencia en la oscuridad medieval.

69 Vid. Ou. Met. 7.552-553; Liu. III 32.2-3; Procop. II 22.1; en Liu. XXV 26-7 y Sil. Ital. XIV 616-618 el tópico se aplica a la igualdad entre enemigos y aliados ante la muerte; ya hemos comentado cómo también afecta por igual a los animales; $c f$. Liu. IV 25-4. 
de la enfermedad, pero sobre todo en el verso «corre la Muerte con iguales pasos» (v. 480), una imagen personificada muy significativa por su tradición iconográfica ${ }^{70}$ y por aunar la siniestra metáfora senecana de la salida de las monstruosidades de los Infiernos ${ }^{71}$ y la profética visión apocalíptica del cuarto jinete ${ }^{72}$.

\section{III.7 Los espacios de la muerte}

La universalidad de la enfermedad se traduce en una ingente cantidad de afectados, moribundos y muertos que copan los espacios públicos y privados, y aquí Trigueros desarrolla una interesante cadencia espacial (vv. 486 ss.): comienza por el lecho, que por metonimia alude al espacio doméstico en el que se dan las relaciones personales truncadas por la peste, estando más cercano el erudito ilustrado a Boccaccio que a las fuentes clásicas, pues registra claramente el abandono de los enfermos; a este ámbito privado pertenece también el tópico de la visita inútil del médico (vv. 492-493), cuyos remedios, como se insiste desde Tucídides, son insuficientes e inicuos ${ }^{73}$. De lo doméstico Trigueros pasa a lo rural (vv. 494 ss.), con una inversión espacial del modelo tucidideo ${ }^{74}$ y motivada, quizá, por las constantes referencias al campo en los poetas latinos como escenario de la mortandad animal y del contagio humano ${ }^{75}$; curiosamente, Trigueros coincide otra vez con Boccaccio, que sitúa en el campo el utópico refugio para los protagonistas del Decamerón. En el texto de Cíane destaca la tétrica descripción del funesto trasiego de los carros de cadáveres, inspirado en los siguientes versos de Séneca:

Un nuevo cortejo es continuamente conducido hasta la Muerte, una larga hilera de afligidas multitudes se apresura hacia los Manes. La triste procesión se detiene y a la muchedumbre que marcha hacia las tumbas no le basta que le abran las siete puertas. Se apila un montón de cadáveres ya un funeral empuja otro funeral que se le une. ${ }^{76}$

\section{III.8 EI sepulcro}

Derivado de los conceptos anteriores (universalidad y trasiego) es el motivo de la transgresión en las costumbres funerarias, especialmente el abandono de los ritos debidos a los familiares muertos (vv. 486-491) y el confinamiento de los cadáveres a sepulcros

\footnotetext{
${ }^{70}$ La Edad Media abundó el tema de la muerte para todos, fruto, al parecer, de los estragos de la Peste Negra en el imaginario colectivo, vid. Mitre Fernández, 2004: 111-134.

${ }_{71}$ Sen. Oed. 160-179; en S. OT 27-30, sin embargo, la imagen es la contraria: el Hades se enriquece con las almas de los muertos.

${ }^{72}$ Apoc. 6.8 .

${ }^{73}$ Cf. Th. II 51.1-2; Lucr. VI 1226-1229; Ou. Met. 7.561-564; Sen. Oed. 70, etc.

${ }^{74}$ En Th. II 52 y Lucr. VI 1260-1266 el contagio sigue la dirección contraria: del campo a la ciudad.

75 Verg. G. 3.474-566; Ou. Met. 7.538-553; Sen. Oed. 133-153.

${ }^{76}$ Sen. Oed. 126-132, trad. Pérez Gómez, 2012.
} 
deshonrosos (vv. 496-499) ${ }^{77}$, dos tópicos que se repiten desde Tucídides y que se han ido adaptando al modus sepeliundi de cada momento ${ }^{78}$.

\section{III.9 Morir es vivir}

La descripción de la peste culmina en la tragedia con una serie de divagaciones acerca de la muerte, que, si bien en circunstancias normales sería objeto privilegiado del temor humano, en momentos de crisis como una epidemia se convierte en algo ansiado, de aquí la inversión connotativa de conceptos como «aliento», «consuelo»y, sobre todo, «muerte» (vv. 504 ss.), pues, entre tanto penar $^{79}$, la muerte es el único alivio, pero ella, caprichosa, ahora ya no asiste equitativamente, sino que se ceba en la desgracia y deja incólume a quien ansía morir, idea retomada también de Séneca:

Postrado ante el altar tiendo mis manos suplicantes.

Pido una muerte pronta para adelantarme

a la ruina de la patria y no caer después de todos

y ser el último cadáver de mi propio reino.

¡Ay, divinidades demasiado crueles! ;Ay, penoso destino!

¿Solo a mí en este pueblo se me niega

una muerte tan dispuesta? ${ }^{80}$

\section{Conclusiones}

La descripción de la peste es un motivo literario que le viene impuesto a Trigueros por dos vías: el argumento mitológico pseudoplutarqueo y los modelos clásicos, especialmente los trágicos, que el erudito dieciochesco ha amplificado y contaminado con elementos procedentes de otras fuentes. Ahora bien, es posible que la inclusión de este tópos no sólo se deba a una cuestión de imitatio classica, sino que las propias características de la literatura neoclásica favorecen y justifican la digresión.

En efecto, a diferencia de los autores clásicos, en los que la descripción de la peste es un relato meramente episódico, insertado en un marco narrativo como parte integrante e indisoluble del mismo ${ }^{81}$, en la literatura europea la peste se convirtió en tema autónomo y central de todo tipo de obras, no sólo médicas. Así, en la Francia del siglo XVIII se dio una abundante producción literaria que tenía como tema central los estragos de las epidemias que asolaron el continente desde la Edad Media hasta la contemporánea y de-

77 El abandono de los contagiados y de las obligaciones es un hecho constatado en brotes de peste reales, cf. Delumeau, 2012: 161-166.

${ }_{78}$ Th. II 52.4; véase el análisis de Gilarrondo Miguel, 2003, que compara los textos de Tucídides, Lucrecio, Procopio, Boccaccio, Defoe, Camus y Saramago; aunque se debe completar con Ou. Met. 7.606-613 y Sen. Oed. 64-70, mucho más relevantes en la tradición occidental que Procopio.

${ }^{79}$ Cf. Lucan. VI 100-103.

80 Sen. Oed. $71-77$.

${ }^{81}$ Nótese ya el cambio operado por Boccaccio, dado que la descripción de la peste es el pretexto para la creación del verdadero marco narrativo de las cien novelle que componen el Decamerón. 
vastadora peste de Marsella de 1720 (extendida por toda Europa, incluida España ${ }^{82}$ ) y se aprovechaba el discurso literario sobre la enfermedad para teorizar acerca de la sociedad, la modernidad, la ciencia y la razón, pero sin abandonar, lógicamente, las descripciones literarias precedentes ${ }^{83}$.

En este sentido, no se puede obviar la impronta dejada por la cultura francesa en general y por la literatura en particular en la España del siglo XVIII ${ }^{84}$, algo de lo que Trigueros, como buen Ilustrado, también fue promotor y partícipe ${ }^{85}$. La descripción de la peste en Cíane responde, por tanto, no sólo a cuestiones de modelos, sino también de gustos y tendencias literarias.

\section{BiBLIOGRAFÍA}

Aguilar Piñal, F. (1968): «La obra 'ilustrada' de don Cándido María Trigueros», RLit, 34, 31-55.

- (1974): Sevilla y el teatro en el siglo XVIII, Oviedo, Universidad.

- (1987): Un escritor ilustrado: Cándido María Trigueros, Madrid, CSIC.

- (1987b): «La continuación de La Galatea por Trigueros», Dicenda, 6, 333-341.

- (1987c): «Las fábulas mitológicas de Conón, traducidas por Cándido María Trigueros (1768)», en AA. VV., Athlon. Satura grammatica in honorem Francisci R. Adrados, Madrid, Gredos, vol. II, 9-14.

- (1999): La biblioteca y el monetario del Académico Cándido María Trigueros (1798), Sevilla, Universidad.

Alsina, J. (1987): «¿Un modelo literario de la descripción de la peste de Atenas?», Emerita, 55, 1-13.

ANDERson, W. S. (1972): Ovid's Metamorphoses books 6-10, Oklahoma, University Press.

ANDIOC, R. (1976): Teatro y sociedad en el Madrid del siglo XVIII, Madrid, Castalia.

BAILEy, C. (1986): Titi Lucreti Cari De rerum natura libri sex, vol. II, Oxford, Clarendon Press.

Berbel Rodríguez, J. J. (2003): Orígenes de la tragedia neoclásica española (1737-1754). La Academia del Buen Gusto, Sevilla, Universidad.

Branca, V. (1975): Bocacio y su época, Madrid, Alianza.

BüChNer, K. (1957): Humanitas Romania. Studien über Werke und Wesen der Römer, Heidelberg, Winter.

Cañas Murillo, J. (2003): «García de la Huerta y la tragedia neoclásica», en J. Huerta Calvo (dir.), Historia del Teatro Español, vol. II: Del siglo XVIII a la época actual, Madrid, Gredos, pp. 1577-1602.

Carrière, Ch., Courdurie, M., Rebuffat, F. (1969): Marseille, ville morte: la peste de 1720, Marseille, Maurice Garçon.

De Lazzer, A. (2000): Plutarco. Paralleli minori, Napoli, M. D’Auria (Corpus Plutarchi Moralium).

Defourneaux, M. (1963): Inquisición y censura de libros en la España del siglo XVIII, Madrid, Taurus.

${ }^{82}$ Vid. Carrière, Courdurie, y Rebuffat, 1969 y sobre sus efectos en España Peset, Mancebo y Peset, 1971; Peñafiel Ramón y Peñafiel Ramón, 1987/1988.

${ }^{83}$ Véanse los documentados trabajos de Jones, 1996 y Gordon, 1997 y para la literatura inglesa la monografía de Gribsy, 2004.

${ }^{84}$ Sin caer en los excesos señalados por Sebold, 1985: 13-40 y 1989: 77-97; acerca del importante referente francés como modelo, antimodelo u objeto de traducción véase la síntesis de Lafarga, 2003

${ }^{85}$ No deja de ser, sin embargo, paradójico que la literatura francesa sea precisamente la más vapuleada por la censura inquisitorial, vid. Defourneaux 1963. 
Delumeau, J. (2012): El miedo en Occidente, Madrid, Taurus.

Detienne, M. (1986): Dioniso a cielo abierto, trad. esp. Barcelona, Gedisa.

Fernández Delgado, J. A. (1996): «Relatos oraculares y modelos de folclore: el caso de Plutarco», en O. Pecere - A. Stramaglia (eds.), La letteratura di consumo nel mondo grecolatino, Cassino, Università, pp. 483-503.

FERNÁNDEZ-GALIANO, M. (1969²): La transcripción castellana de los nombres propios griegos, Madrid, SEEC.

Franco Durán, M. ${ }^{a}$ J. (1998): «La función de la mitología clásica en el teatro del Siglo de Oro», en C. StrosetzKi (ed.), Teatro español del Siglo de Oro, Frankfurt am Main-Madrid, Verbuert-Iberoamericana, pp. 119-130.

García Garrosa, M. J. (1992): «Diderot y Trigueros: sobre las posibles fuentes de El precipitado», RLit, 54, 183-200.

GIL, J. (1981): «Epigrafía antigua y moderna», Habis, 12, 153-176.

Gilarrondo Miguel, Ó. (2003): «La tradición clásica del tema de la peste: los ritos funerarios», en AA. VV., Vrbs Aeterna. Roma, entre la Literatura y la Historia. Homenaje a la profesora Carmen Castillo, Pamplona, EUNSA, pp. 481-491.

Glendinning, N. (1979): Historia de la literatura española 4. El siglo XVIII, trad. esp. Barcelona, Ariel.

Gordon, D. (1997): «The City and the Plague in the Age of Enlightenment», YFS, 92, 67-87.

GriBsy, B. L. (2004): Pestilence in Medieval and Early Modern English Literature, London-New York, Routledge.

Grimm, J. (1965): Die literarische Darstellung der Pest in der Antike und der Romania, München, W. Fink.

Harrison, E. L. (1979): «The Noric Plague in Vergil's third Georgic», en F. CaIrns (ed.), Papers of the Liverpool Latin Seminar, vol. II, Liverpool, University Press, pp. 1-65.

Hernández Esteban, M. (2011): Giovanni Boccaccio. Decamerón, 9. a ed., Madrid, Cátedra.

IbáÑEz CHACón, Á. (2007): «El mitógrafo Conón en la Biblioteca de Focio», Erytheia, 28, 41-65.

- (2008/2009): «La violación como tópico en los Parallela minora», Ploutarchos, 6, 3-14.

- (2010): «Mito griego e Historia de Roma en los Parallela minora», en C. Macías Villalobos - V. E. Rodríguez Martín (eds.), Por la senda de los clásicos. Studia selecta in honorem María Dolores Verdejo oblata, Málaga, Editorial 33, pp. 287-333.

- (2012): «Los Parallela minora como pseudepigrafía: criterios externos (Clemente de Alejandría y Lido)», en J. Martínez (ed.), Mundus vult decipi. Estudios interdisciplinares sobre falsificación textual y literaria, Madrid, Ediciones Clásicas, pp. 159-170.

JACOBY, F. (1940): «Die Überlieferung von ps.-Plutarchs Parallela minora und die Schwindelautoren», Mnemosyne 8, 73-144.

Jeanmaire, H. (19702): Dionysos. Histoire du culte de Bacchus, Paris, Payot.

Jones, C. (1996): «Plague and Its Metaphors in Early Modern France», Representations, 53, 97-127.

LAFARGa, F. (2003): «La presencia francesa en el teatro necoclásico», en J. Huerta Calvo (dir.), Historia del Teatro Español, vol. II: Del siglo XVIII a la época actual, Madrid, Gredos, pp. 1737-1759.

Lens Tuero, J. (2003): «Mito y utopía en la historiografía helenística», en J. A. LóPez Férez (ed.), Mitos en la literatura griega helenística e imperial, Madrid, Ediciones Clásicas, pp. 113-135.

Loraux, N. (2004): Madres en duelo, Madrid, Abada.

LuPPE, W. (2001): «P. Berol. inv. 11 056: ein Roman-Fragment?», APF, 47, 20-25.

Martin, M., Devallet, G. (1992): Silius Italicus. Les Guerres Puniques, IV, Paris, Les Belles Lettres. 
Mitre Fernández, E. (2004): Fantasmas de la sociedad medieval. Enfermedad, peste, muerte, Valladolid, Universidad.

Müller, W. (1981): «Mythologische Erzählung (Kyane)», en Papyri edited in Honor of E. G. Turner, Graeco-Roman Memoirs, 68, London, pp. 63-65.

Pabón, C. T. (1972): «Don Cándido María Trigueros y su tragedia inédita Cíane de Siracusa», EClás 16, 229-245.

Pailler, J.-M. (1988): La répression de 186 av. JC à Rome et en Italie, Rome, Ecole française de Rome.

- (1995): Bacchus. Figures et pouvoirs, Paris, Les Belles Lettres.

Palacios Fernández, E. (1996): «Teatro», en F. Aguilar Piñal (eds.), Historia literaria de España en el siglo XVIII, Madrid, Trotta-CSIC, pp. 125-233.

Parker, R. (1983): Miasma. Pollution and Purification in Early Greek Religion, Oxford, Clarendon Press.

Pellizer, E. (1991): La peripezia del eletto, Racconti eroici della Grecia antica, Palermo, Sellerio.

Peñafiel Ramón, A., Peñafiel Ramón, C. (1987/1988): «Repercusión de la epidemia de peste marsellesa de 1720 en la ciudad de Murcia. Realidad de un gran miedo», Contrastes, 3-4, 53-70.

Pérez Gómez, L. (2012): Séneca. Tragedias completas, Madrid, Cátedra.

Peset, M., Mancebo, P., Peset, J. L. (1971): «Temores y defensa de España frente a la peste de Marsella de 1720», Asclepio, 23, 131-187.

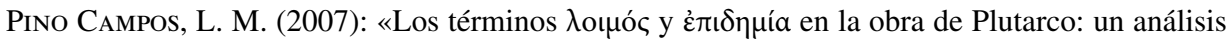
semántico», en J. M. ${ }^{a}$ Nieto Ibáñez \& R. López LóPez (eds.), El amor en Plutarco (IX Simposio Internacional de la Sociedad Española de Plutarquistas), León, Universidad de León, pp. 847-857.

Pino Campos, L. M., Hernández González, J. (2008): «Los conceptos de peste y epidemia: semántica y lexicografía», RFLL, 26, 191-204.

Pomelli, P. (2010): «L'origine dei Mirmidoni: formiche, eroi ed altro ancora», en S. BETA y F. MARZARI (eds.), Animali, ibridi e mostri nella cultura antica, Firenze, Edizioni Cadmo, pp. 167-208.

RAmírez DE Verger, A. (1985): «La peste como motivo literario (a propósito de Coripo, Ioh. III, 338-379)», CFC, 19, 145-156.

Ruiz Castellanos, A. (2012): «La etiología como forma de composición de la Peste de Atenas en Tucídides y en Lucrecio», $C F C(L), 32,7-34$.

SEBOLd, R. P. (1973): «El incesto, el suicidio y el primer Romanticismo español», HR, 41, 669-692.

- (1985): Descubrimiento y fronteras del neoclasicismo español, Madrid, Cátedra.

- (1989): El rapto de la mente. Poética y poesía dieciochescas, Madrid, Anthropos.

- (2001): La perduración de la modalidad clásica. Poesía y prosa españolas de los siglos XVII a XIX, Salamanca, Universidad.

- (2008): Ignacio de Luzán. La poética, Madrid, Cátedra.

Segal, Ch. (2005): «Il corpo e l'io nelle Metamorfosi di Ovidio», en A. Barchiesi (ed.), Ovidio: Metamorfosi, Volume I (Libri I-II), Milano, Fondazione Lorenzo Valla/Arnoldo Mondadori Editore, pp. XV-CI.

Seznec, J. (1983): Los dioses de la Antigüedad en la Edad Media y el Renacimiento, Madrid, Taurus.

Steel, D. (1981): «Plague Writing: From Boccaccio to Camus», JES, 11, 88-110.

Torres Esbarranch, J. J. (1989): «Notas sobre la descripción tucididea de la peste de Atenas», Mayurga, 22, 953-961.

Ventricelli, L. (2004): «Ciane e Cianippo: percoris teatrali di una censura», AFLFB, 47, 365-396.

West, D. (1979): «Two Plagues. Virgil, Georgics 3.478-566 and Lucretius, 6.1090-1286», en D. West

- T. Woodman, Creative imitation and Latin literature, Cambridge, University Press, pp. 71-88.

Ziegler, K. (1965): Plutarco, Brescia, Paideia. 


\section{ApPendix: la PeSte de Siracusa SEgún Trigueros}

Presentamos la edición del pasaje objeto de nuestro comentario siguiendo como texto base el $m s .17294$ (al que denominamos L) y acompañándolo de las lecturas divergentes de los otros dos manuscritos de la Biblioteca Nacional ( $m s .18072=\mathbf{C}$ y $m s .16226=\mathbf{T}$ ). Hemos actualizado la ortografía, los signos de puntuación y numerado los versos, pues en ninguno de los originales aparece una numeración seguida, sino que al final de las páginas (L) o al final de los actos (C) Trigueros hace recuento de versos.

\section{CORO}

No os admiréis, Pergandro; en esta corte todo es justo dolor, justa tristeza.

Desde la noche del primero día, en que los Bacanales se celebran, se llora desolada Siracusa ${ }^{87}$ de una peste cruel que la despuebla $\mathrm{y}$, en vez de la alegría que esperaba, vino el horror, la pesadumbre y queja. Si de justo dolor morir no quieres, de aquí no salgas, la ciudad no veas: todo en ella es terror y pesar todo. La ejecutiva Muerte corre, vuela, y la desolación de nuestras gentes en su segur a todas partes lleva. En los amantes brazos de su esposo se mira allí expirar la joven tierna; él, lleno de dolor, busca a su padre, cuéntale el mal, su corazón penetra $y$, cuando se consuela uno con otro, pasa la muerte y a los dos se lleva. Una antigua criada que lo ha visto, corre a la madre, su desdicha cuenta, $\mathrm{y}$, aun antes de que acabe de decirlo, el aliento le falta en su presencia. La viuda madre, congojada y triste, oye llorar un niño que le queda

${ }^{434}$ os admiréis] lo extrañéis $\mathbf{C}$.

438 llora desolada] se halla perseguida $\mathbf{C}$.

${ }_{440}$ esperaba] aguardaban $\mathbf{C}$.

${ }^{444}$ todo en ella] en ella todo $\mathbf{C}$.

${ }_{446}$ y la desolación de nuestras gentes] y la desolación, la pena, el luto $\mathbf{T}$. pasea $\mathbf{T}$.

447 en su segur a todas partes lleva] en su guadaña a todas partes lleva $\mathbf{C}$, de casa en casa en su segur

449 se mira allí expirar la joven tierna] expira allí la jovencilla tierna $\mathbf{C}$.

${ }^{455}$ desdicha] pesar $\mathbf{T}$.

456 decirlo] contarlo $\mathbf{C}$.

458 congojada y triste] triste y congojada $\mathbf{T}$. 
y que a sus maternales pechos cría; 460 corre desalentada, a verle llega, le pone en su regazo y, al mirarle, cuasi se olvida de sus muchas penas; a su boca suave amante arrima el blanco pecho y, cuando la consuela este único resto de su casa, le ve expirar entre sus manos mesmas. ¿Quién que no sea madre saber puede de tan justo dolor la fuerza inmensa?

Alza el grito a los cielos, un momento después queda entredicha, su flaqueza en furor se convierte, con los dioses habla: ya los maldice, ya les ruega; lo que dice no sabe y aun se olvida de su mismo dolor y de su queja.

A los que vio expirar, los llama y busca, y es un nuevo tormento cuanto encuentra. Pide a gritos la muerte, mas la muerte va buscando quien menos males tenga. Furiosa por morir abraza a todos cuantos murieron de la peste fiera, sin lograr un consuelo tan funesto como el común peligro que desea. Siracusa está llena de estos ayes en las cinco ciudades que la pueblan: en Naxos, Acradina, la Gortuna, Epípolas, señor, y Ciudadnueva corre la muerte con iguales pasos.

Todo es rumor y cuita alharaquienta, muerte, desolación, ansia, fatiga,

lástima, horror, pesar, llanto, miseria.

Cual a su hermano pierde, cual su amigo; ésta huérfana queda, viuda aquélla. Muertos y moribundos en un lecho de pálido terror los sanos llenan:

${ }^{461}$ corre desalentada, a verle llega] corre turbada y a la cuna llega $\mathbf{C}$.

463 muchas penas] grandes penas $\mathbf{T}$.

469 de tan justo dolor la fuerza inmensa] este fuerte (triste sobrescrito) dolor la inmensa fuerza $\mathrm{C}$, de tan justo dolor la inmensa fuerza $\mathbf{T}$.

470-72 Versos de orden alterado y con partes omitidas en $\mathbf{C}$.

474 lo que dice no sabe] no sabe lo que dice $\mathbf{C}$.

${ }^{476}$ A los que vio expirar, los llama y busca] corre toda la casa, a todos busca $\mathbf{C}$.

479 va buscando quien menos males tenga] viene al que huye; al que la llama deja $\mathbf{T}$.

480 Furiosa por morir] ansiosa de morir $\mathbf{C}$.

482 sin lograr] y aún no logra $\mathbf{C}$, y no logra $\mathbf{T}$.

${ }^{484}$ Siracusa] la ciudad $\mathbf{C}$; ayes] males $\mathbf{T}$.

485 en las cinco ciudades que la pueblan] en todas las ciudades que la pueblan $\mathbf{T}$, om. $\mathbf{C}$.

486-87 om. C T.

${ }^{488-525} \mathrm{om}$. C., pero se encuentran copiados de forma casi ilegible al final del acto, h. $232 \mathrm{r}$. 
los huye el más amigo, desampara el hijo al padre; las amantes quejas del bello joven aún no son bastantes a que le dé favor la esposa tierna; si un médico se mueve y les asiste no da la vida y con la muerte encuentran. ${ }^{109}$ ¡Cuántos huyen al campo! Mas al campo va con ellos su muerte y las ajenas. Tristes carros se cruzan por las calles en que a humilde sepulcro en dura tierra arrastran la mitad de Siracusa.

¡Qué de horrores en ellos! ¡Qué miserias!

Su horrible palidez pinta la muerte en los semblantes de los que los llevan y por su pie se van a su sepulcro: entre los muertos, los que aún viven, penan. Cual despide el aliento en un suspiro, cual grita que está sano, cual alienta a expirar con valor a los que mueren, y acaba aun antes que los que consuela, de una triste constancia les da ejemplo. Cual pide que le maten por clemencia, el que da más pesar y hace más falta es el primero que la peste siega y sólo el que en la muerte halla consuelo suspira sano: tan amargas penas y tan cruel castigo nos oprime; no extrañes pues, señor, lo que se quejan. En el remedio de comunes riesgos su real cuidado Cianipo emplea y Cíane, ofreciendo sacrificios en aquel templo, por su pueblo ruega. Voy a decir, señor, que habéis venido. No es mucho en tal estado no lo sepan.

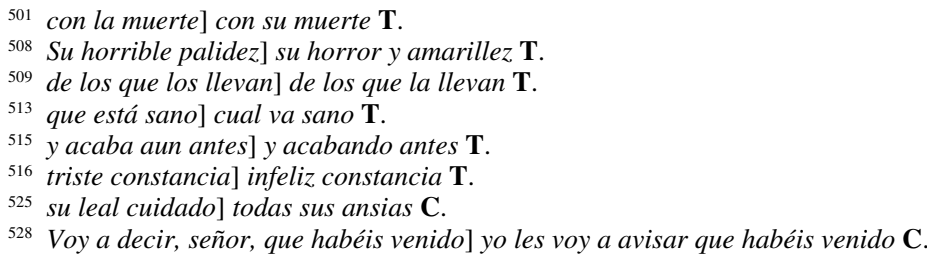

